\title{
Assay of Methylmalonic Acid in the Serum of Patients with Cobalamin Deficiency Using Capillary Gas Chromatography-Mass Spectrometry
}

Sally P. Stabler, Paul D. Marcell, Elaine R. Podell, Robert H. Allen, and John Lindenbaum*

Divisions of Hematology and Oncology, Department of Medicine, and Departments of Biochemistry, Biophysics, and Genetics, University of Colorado Health Sciences Center, Denver, Colorado 80262; and *Departments of Medicine, Harlem Hospital

Center and College of Physicians and Surgeons, Columbia University, New York, New York 10032

\begin{abstract}
To determine the incidence of elevated levels of serum methylmalonic acid in patients with cobalamin deficiency, we utilized a new capillary gas chromatographic-mass spectrometric technique to measure methylmalonic acid in the serum of 73 patients with clinically confirmed cobalamin deficiency. Values ranged from 55 to $22,300 \mathrm{ng} / \mathrm{ml}$, and 69 of the 73 patients had values above the normal range of $19-76 \mathrm{ng} / \mathrm{ml}$ as determined for 50 normal blood donors. In the cobalamin-deficient patients, serum methylmalonic acid was significantly correlated with the serum folate level and the degree of neurologic involvement. Some patients with pernicious anemia who were intermittently treated with cyanocobalamin were found to have elevated serum levels of methylmalonic acid while free of hematologic and neurologic abnormalities. A cobalamin-deficient patient is described with a normal serum cobalamin and an elevated serum methylmalonic acid. We conclude that the ability to measure methylmalonic acid in human serum will be useful in studies designed to determine the incidence of cobalamin deficiency in various patient populations.
\end{abstract}

\section{Introduction}

Previous investigators have shown that most patients with cobalamin $\left(\mathrm{Cbl} \text {, vitamin } \mathrm{B}_{12}\right)^{1}$ deficiency have elevated levels of methylmalonic acid in their urine (1-12). The origin of the methylmalonic acid has recently been elucidated (13) and is illustrated in Fig. 1. In Cbl deficiency, reduced levels of adenosylCbl result in decreased activity of L-methylmalonyl-coenzyme A (CoA) mutase and a resultant increase in intracellular levels of L-methylmalonyl-CoA. D-methylmalonyl-CoA is also elevated due to the activity of D,L-methylmalonyl-CoA racemase (14) and is cleaved to coenzyme $A$ and methylmalonic acid by the recently recognized and characterized enzyme, D-methylmalonyl-CoA hydrolase (13). Methylmalonic acid is then released into blood in unknown amounts and is excreted in the urine. In normal individuals (15) and laboratory animals (13), about

Address correspondence to Dr. Allen, Division of Hematology, Campus Box B170, University of Colorado Health Sciences Center, $4200 \mathrm{E}$. Ninth Ave., Denver, CO 80262.

Received for publication 19 August 1985 and in revised form 16 December 1985.

1. Abbreviations used in this paper: $\mathrm{Cbl}$, cobalamin; $\mathrm{CN}-\mathrm{Cbl}$, cyano-Cbl; $\mathrm{CoA}$, coenzyme A; MCV, mean corpuscular volume; $\mathrm{LDH}$, lactate dehydrogenase.

J. Clin. Invest.

(C) The American Society for Clinical Investigation, Inc.

0021-9738/86/05/1606/07 \$1.00

Volume 77, May 1986, 1606-1612
$70 \%$ of methylmalonic acid in blood is metabolized to unknown products via undefined pathways and only about $30 \%$ is excreted in the urine.

At the present time, the serum $\mathrm{Cbl}$ assay is essentially the only laboratory test generally available for use in determining if a patient is Cbl-deficient, and this limitation has been widely recognized (16-19). Low serum Cbl values in patients without hematologic abnormalities are frequently encountered in screening studies $(16-19)$, in the elderly $(20,21)$, and in patients with certain neuropsychiatric abnormalities $(22,23)$, but their significance has been difficult, if not impossible, to determine. More rarely, diagnostic problems can also develop in patients with hematologic abnormalities, since serum Cbl levels may be normal in Cbl-deficient patients who have elevated levels of Cblbinding proteins (24). Additional diagnostic tests like urinary methylmalonic acid (1-12) and the deoxyuridine suppression test $(25,26)$ have not been widely used and, thus, a definite need exists for additional tests that could be used to evaluate patients for $\mathrm{Cbl}$ deficiency and to evaluate the sensitivity and specificity of the serum $\mathrm{Cbl}$ assay.

We have recently developed a new capillary gas chromatography-mass spectrometry method that is capable of detecting and quantitating methylmalonic acid in normal human serum (15). We now report the use of this method to measure methylmalonic acid in the serum of patients with clinically confirmed Cbl deficiency.

\section{Methods}

Assay of methylmalonic acid and succinic acid. Methylmalonic acid and succinic acid were assayed using capillary gas chromatography-mass spectrometry as previously described in detail (15). Briefly, $50 \mu \mathrm{l}$ of $\mathrm{H}_{2} \mathrm{O}$ containing $200 \mathrm{ng}$ of [methyl- ${ }^{2} \mathrm{H}_{3}$ ] methylmalonic acid $(>99 \%)$ and 2,000 ng of $\left[1,4{ }^{13} \mathrm{C}_{2}\right]$ succinic acid $(>99 \%)$ is added to $50-500 \mu$ l of human serum and the total volume, if needed, is brought up to $550 \mu \mathrm{l}$ with $\mathrm{H}_{2} \mathrm{O}$. The samples are then extracted with ether, partially purified by high performance liquid chromatography using an anion exchange resin at pH 2, repeat ether extraction, formation of the $t$-butyldimethylsilyl derivatives using $N$-methyl- $N(t$-butyldimethylsilyl)trifluoroacetamide, extraction of the derivatives into hexane, and volume reduction using a stream of nitrogen. The samples are analyzed on a Durabond DB-5 fused silica capillary column $(30 \mathrm{~m} \times 0.25 \mathrm{~mm}$ i.d., $0.25 \mu \mathrm{m}$ film thickness) from J \& W Scientific, Inc. (Rancho Cordova, CA) and a HewlettPackard Co. (Palo Alto, CA) 5992B gas chromatography-mass spectrometer equipped with a falling-needle injector. Quantitation is based on the ratio of the areas of the base peak ion $\mathbf{2 8 9} .2$ for the methylmalonic acid and succinic acid derivatives, which elute at different times, to the areas of the base peak ions of 292.2 and 291.2 for the derivatives of their respective stable isotope internal standards. Methylmalonic acid and succinic acid are very stable in collected serum, as no change or trend in values for these two dicarboxylic acids was noted in a sample of pooled normal human serum that was frozen, thawed, and assayed 17 different times over a 10-mo period (15). Values for serum methylmalonic acid obtained with blood samples that were drawn and immediately centri- 


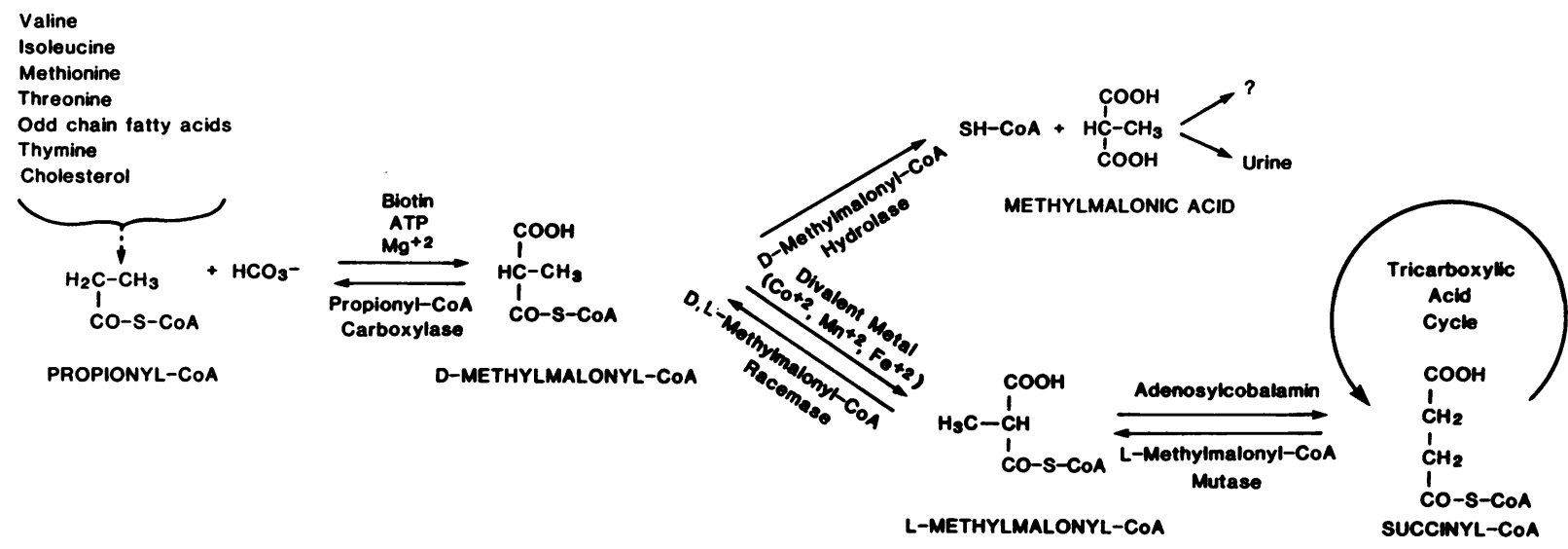

Figure 1. Pathway for the formation of methylmalonic acid. Based on studies performed with $\left[{ }^{14} \mathrm{C}\right.$-methyl]methylmalonic acid, $\sim 30 \%$ of serum methylmalonic acid is excreted in the urine and $70 \%$ is metabolized to unknown products via undefined pathways (13).

fuged at $4^{\circ} \mathrm{C}$ were the same as those obtained with portions of the same blood samples that were incubated at room temperature for $1-24 \mathrm{~h}$ before centrifugation (15). Values for serum succinic acid increased about $90 \%$ over the 24-h time period (15). Values for urine methylmalonic and succinic acids were unchanged when urine samples were incubated at room temperature for 0-24 h (15). The internal standards of methylmalonic acid and succinic acids were stable for over $1 \mathrm{yr}$, based on their gas chromatographic-mass spectrometric behavior, when stored at $-20^{\circ} \mathrm{C}$ in between numerous freezings and thawings over this time period.

Subjects and patients. Serum samples from 50 normal blood donors, 25 males and 25 females, ranging in age from 18 to $65 \mathrm{yr}$ were obtained as described previously (15). Patient samples were selected by Dr. Lindenbaum from an extensive serum collection that has been assembled over the past $15 \mathrm{yr}$. The diagnosis of $\mathrm{Cbl}$ deficiency was based on low serum Cbl levels, megaloblastic bone marrow morphology, appropriate hematologic or neurologic abnormalities, and a significant response to treatment with parenteral Cbl. The diagnosis of pernicious anemia was based on an abnormal Schilling test that corrected with exogenous intrinsic factor and/or the presence of anti-intrinsic factor-blocking antibodies in the serum. The diagnosis of folate deficiency was based on low serum folate values, normal or elevated serum $\mathrm{Cbl}$ values, megaloblastic bone marrow morphology, appropriate hematologic abnormalities, and a history of alcoholism and poor diet. The samples in the Cbl-deficient infrequently treated group were from patients with pernicious anemia who were previously diagnosed as Cbl-deficient as described above, but who received only intermittent treatment with parenteral $\mathrm{Cbl}$ at intervals of 6-9 mo due to poor compliance or as part of studies of Cbl requirements to be reported elsewhere. They had low, borderline, or normal levels for serum $\mathrm{Cbl}$, lacked hematologic and neurologic abnormalities, and were asymptomatic at the time the samples were collected. Serum Cbl levels were assayed using the Lactobacillus leichmannii method or a number of radiodilution assays utilizing purified intrinsic factor or gastric juice with more than $95 \%$ of $\mathrm{Cbl}$ binding activity due to intrinsic factor. Serum folate was assayed with the Lactobacillus casei method or by milk binder radiodilution assay. All of the patients' samples were coded in a manner such that the categories to which they belonged and the number of patients in each category were not known by the personnel involved in performing the methylmalonic acid and succinic acid assays, until after the results were reported to Dr. Lindenbaum.

Statistical methods. A number of factors were examined individually for possible relationships with serum methylmalonic acid and succinic acid. For factors that were discrete, such as sex, race, and diagnosis, the Wilcoxon two-sample test was used to determine the significance of the relation. For assessing possible relationships with neurologic severity, groups 0,1 , and 2 (as defined in Table I) were combined and compared with combined groups 3 and 4 . Factors that were continuous, such as age or mean corpuscular volume (MCV), were examined using Spearman correlation coefficients.

\section{Results}

The values obtained for serum methylmalonic acid and succinic acid for the normal subjects and patients in the various categories are shown in Fig. 2. In the Cbl-deficient group, 69 of the 73 patients had values for methylmalonic acid that were above the normal range of $19-76 \mathrm{ng} / \mathrm{ml}$. The highest value was $22,300 \mathrm{ng} /$ $\mathrm{ml}$ and the median value was $1,100 \mathrm{ng} / \mathrm{ml}$. 5 of the 16 folatedeficient patients had mild elevations of serum methylmalonic acid with the highest value being $140 \mathrm{ng} / \mathrm{ml} .7$ of 15 samples from the Cbl-deficient infrequently treated patients who lacked hematologic and neurologic abnormalities had elevated values that ranged as high as $175 \mathrm{ng} / \mathrm{ml}$. Of these seven samples, serum L. leichmannii $\mathrm{Cbl}$ concentrations were low $(88-165 \mathrm{pg} / \mathrm{ml})$ in six and normal $(275 \mathrm{pg} / \mathrm{ml})$ in one. All seven samples gave low Cbl values $(85-155 \mathrm{pg} / \mathrm{ml})$ with radiodilution assay using purified intrinsic factor. Of the eight samples with normal levels of methylmalonic acid, serum $L$. leichmannii $\mathrm{Cbl}$ was low in four.

Elevated values for serum succinic acid were observed in 19 of the $73 \mathrm{Cbl}$-deficient patients, 10 of the 16 folate-deficient patients, and 8 of the $15 \mathrm{Cbl}$-deficient infrequently treated patients. The reason for these elevations is unknown, but could be related to variations in the time that blood is allowed to stand before the serum is separated, since we have found (15) that values for serum succinic acid may double when blood is allowed to stand for $24 \mathrm{~h}$ at room temperature before centrifugation. Values for serum methylmalonic acid do not change over this time period (15).

Clinical data concerning the 73 patients with Cbl deficiency are presented in Table I where they are arranged in decreasing order with respect to their serum methylmalonic acid levels. There was a significant correlation between serum methylmalonic acid and serum folate $(r=0.45 ; P<0.001)$. The correlation was present in samples measured by the $L$. casei serum folate method $(r=0.46 ; P<0.01)$ as well as the radioassay technique ( $r=0.66 ; P<0.001)$. Patients with more severe neurologic abnormalities (groups 3 and 4) had higher serum methylmalonic acid levels (mean $\pm \mathrm{SD}, 5077 \pm 6073$, median $3685 \mathrm{ng} / \mathrm{ml}$ ) than those with milder abnormalities (groups 1 and 2, mean $2083 \pm 2866$, median $879 \mathrm{ng} / \mathrm{ml}$ ) or no evidence of neurological involvement (group 0, mean 1154 \pm 1468 , median $409 \mathrm{ng} / \mathrm{ml}$ ) $(P<0.01$ for groups 3 and 4 vs. $0-2$ ).

Serum folate levels correlated with serum methylmalonic acid regardless of neurologic status ( $r$ for methylmalonic acid 


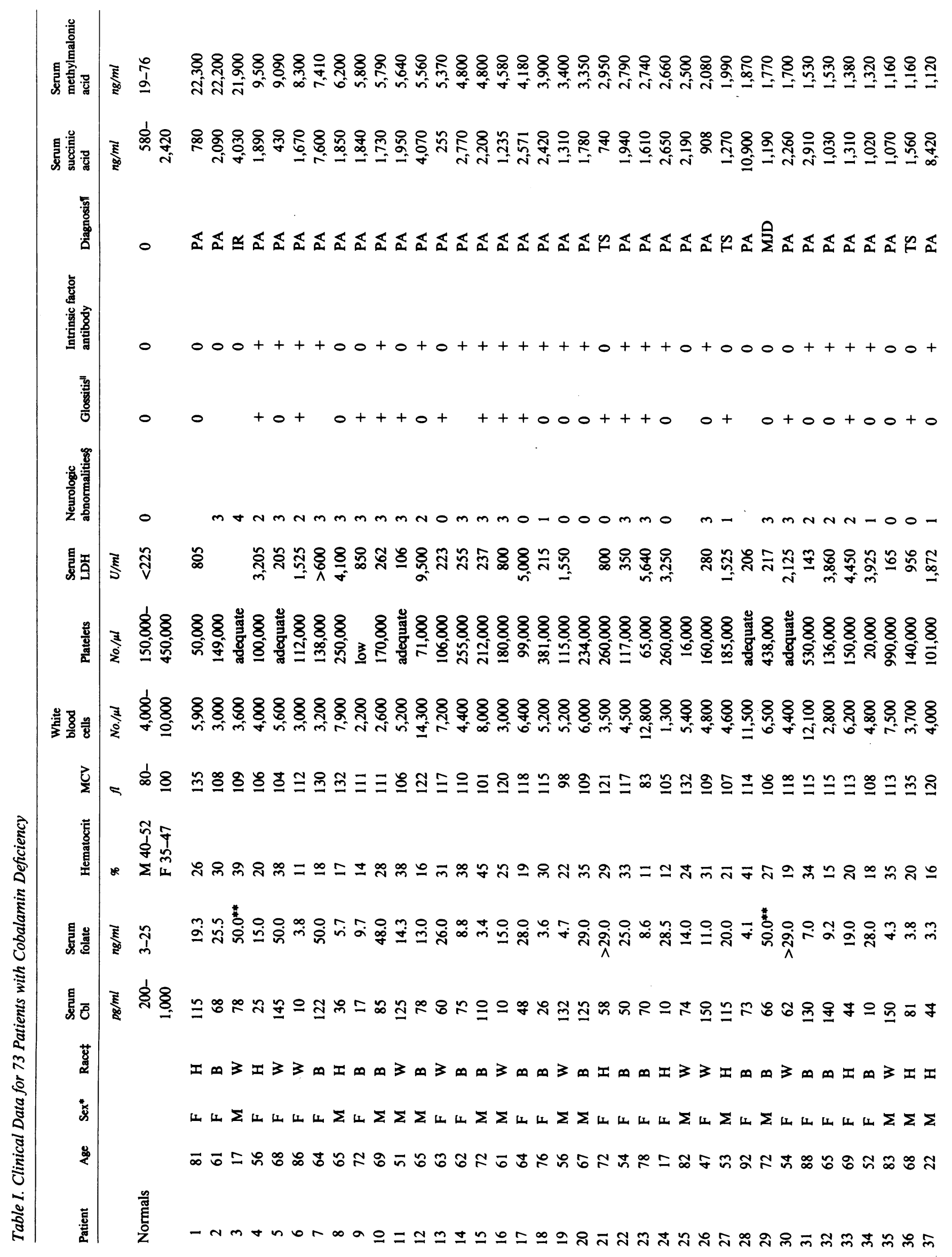




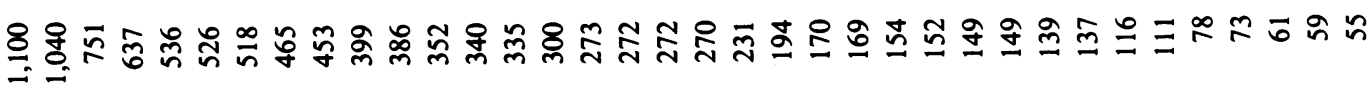

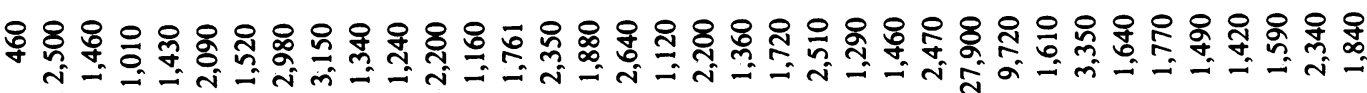
$\cong 0$

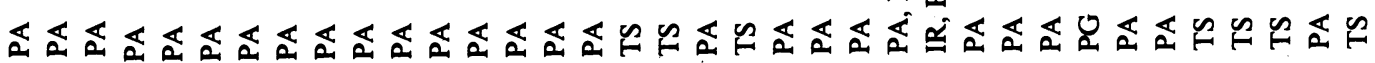
$0++0+++00+++0+++00+0+0++0++00++000+0$ $+++0+00++0++0+0+0000++000000+0000$

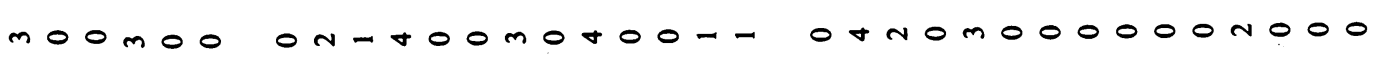

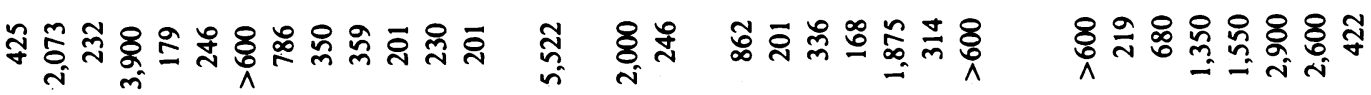

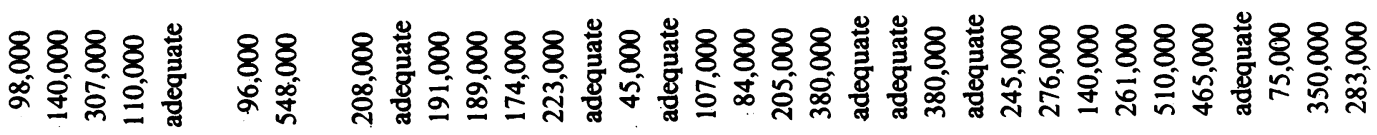

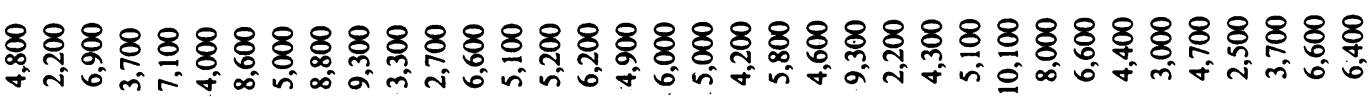

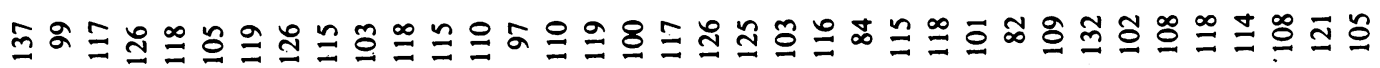

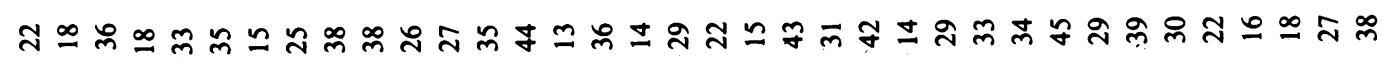

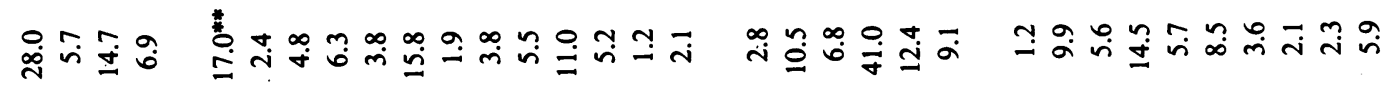

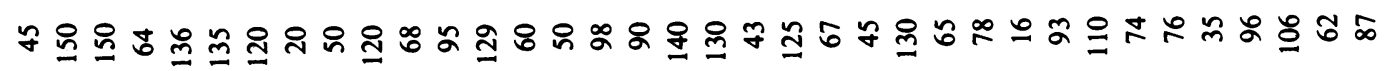

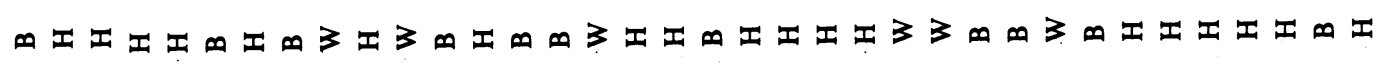

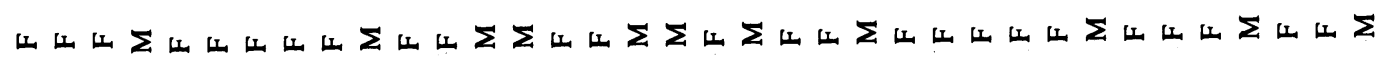
๓

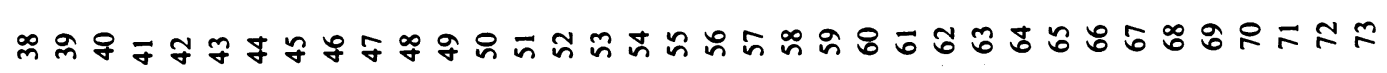



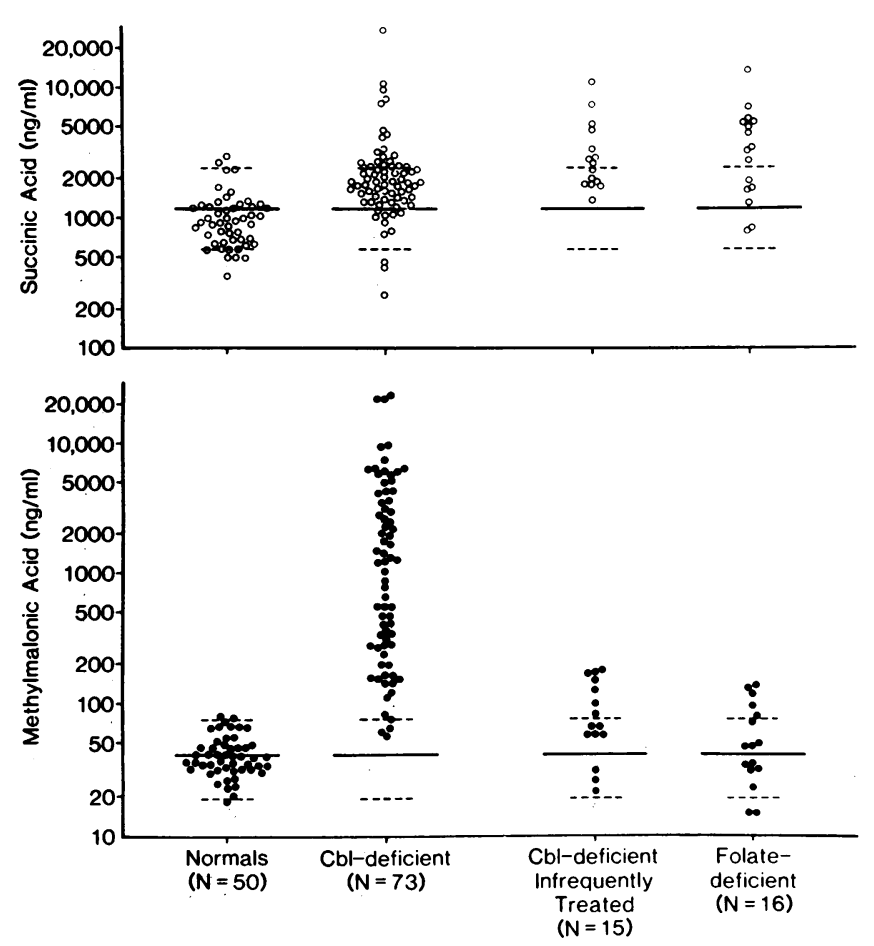

Figure 2. Levels of serum methylmalonic acid (bottom) and serum succinic acid (top) in patients with clinically confirmed Cbl deficiency, folate deficiency, and Cbl-deficient infrequently treated patients who had no hematologic or neurologic abnormalities using capillary gas chromatography-mass spectrometry. The normal range for methylmalonic acid is $19-76 \mathrm{ng} / \mathrm{ml}$, and $580-2420 \mathrm{ng} / \mathrm{ml}$ for succinic acid. These ranges were calculated as the mean \pm 2 SD after log transformation to correct for skewness towards higher values.

vs. folate in patients without neurologic disorders, $0.58 ; n=27$; $P<0.01)$. Although serum folate concentrations were higher in patients with more severe neurological abnormalities (mean serum folate in groups 3 and $4,20.9 \pm 16.9$ vs. $10.1 \pm 8.7 \mathrm{ng} / \mathrm{ml}$ in groups $0-2, P<0.005$ ), the association of higher serum methylmalonic acid levels with advanced neurological involvement appeared to be independent of folate status. In patients with serum folate levels below $15 \mathrm{ng} / \mathrm{ml}$, mean serum methylmalonic acid in groups 3 and 4 was $3189 \pm 2317 \mathrm{ng} / \mathrm{ml}$ vs. $1030 \pm 1795$ $\mathrm{ng} / \mathrm{ml}$ in groups $0-2(P<0.005)$; serum folates did not differ significantly between the two subgroups $(7.5 \pm 3.3$ vs. $6.0 \pm 3.8$ $\mathrm{ng} / \mathrm{ml}$, respectively, $P>0.25$ ).

There was a negative correlation between the platelet count and serum methylmalonic acid levels $(r=-0.30 ; P<0.05)$. However, the correlation was no longer significant if patients with more severe neurologic abnormalities (groups 3 and 4) were omitted from the analysis $(r=-0.26 ; P>0.05)$ or if patients with elevated serum folates were omitted $(r=-0.23 ; P>0.05)$. Patients with pernicious anemia had higher values for serum methylmalonic acid (mean, $2968 \pm 4387 \mathrm{ng} / \mathrm{ml}$ ) than those with tropical sprue (714 $\pm 1007, P<0.004$ using Mann-Whitney test); when corrected for the generally lower serum folate values and less severe neurologic involvement in the patients with tropical sprue, however, the difference was no longer significant. Patients with glossitis had higher serum methylmalonic acid values than patients without tongue signs or symptoms; however, 13 of the 16 patients with glossitis with serum levels of methylmalonic acid above the median for the entire group of 73 patients had severe neurologic involvement, elevated serum folate values, or both.

Serum methylmalonic acid was not correlated with serum $\mathrm{Cbl}(r=-0.09$ for all patients; $r=0.12$ for microbiologic assay; and -0.09 for radioassays, $P>0.4$ in each instance). Serum methylmalonic acid was not significantly correlated with $\mathrm{MCV}$ $(r=0.07, P>0.05)$, white blood cells $(r=-0.08 ; P>0.3)$, or hematocrit $(r=-0.12 ; P>0.4)$. All of the 12 patients with normal hematocrits had elevated serum methylmalonic acid levels (range $116-4800 \mathrm{ng} / \mathrm{ml}$ ). There was no correlation between serum methylmalonic acid and age, sex, race, duration of symptoms, extent of weight loss, or serum levels of iron, lactate dehydrogenase (LDH), bilirubin, or albumin.

Four patients with untreated Cbl deficiency (Nos. 70-73, Table I) had serum methylmalonic acid levels within the normal range. Three had tropical sprue. One of the four had impaired proprioception and vibration sense without neurological symptoms. There were no clinical or laboratory features that differentiated these patients from those with elevated serum methylmalonic acid concentrations.

Values for serum succinic acid did not correlate with any of the parameters studied, including serum methylmalonic acid, and significant differences were not observed between any of the various subgroups.

Fig. 3 shows sequential levels of serum and urine methylmalonic acid in a patient with classic pernicious anemia, beginning at the time of diagnosis and continuing over the first $13 \mathrm{~d}$ after treatment with parenteral Cbl. Both values were markedly elevated before treatment, both decreased at similar rates after treatment, and both were just above the upper limit of normal on day 13. This suggests that measurements of serum and urine methylmalonic acid would correlate well with one another as diagnostic tests for $\mathrm{Cbl}$ deficiency, but a large number of additional patients must be studied before this can be concluded with certainty.

Table II contains data regarding a 95-yr-old white female in whom an elevated serum methylmalonic acid level preceded a

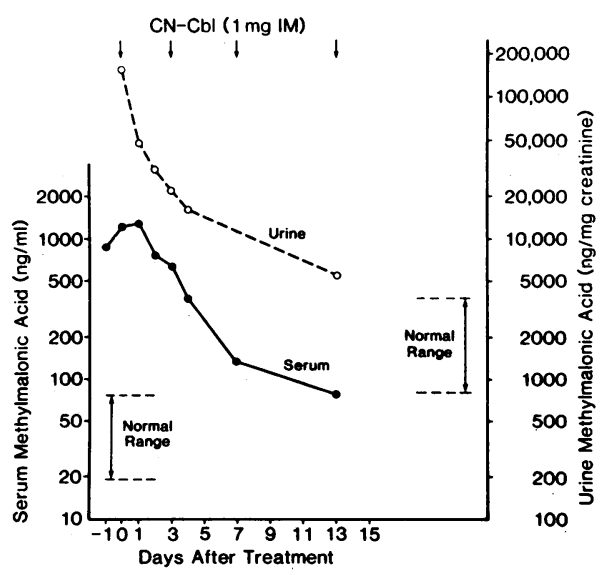

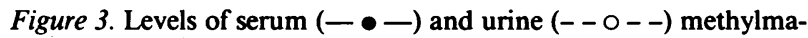
lonic acid in a patient with pernicious anemia before and after treatment with cyano $(\mathrm{CN})-\mathrm{Cbl}$ using capillary gas chromatography-mass spectrometry. The patient was a 32 -yr-old white male with pancytopenia, megaloblastic bone marrow findings, a serum $\mathrm{Cbl}$ value of 43 $\mathrm{pg} / \mathrm{ml}$, serum anti-intrinsic factor-blocking antibodies, and an abnormal Schilling test that corrected with exogenous intrinsic factor. 
Table II. Studies on a Cbl-deficient Patient with an Elevated Methylmalonic Acid and a Normal Serum Cbl

\begin{tabular}{|c|c|c|c|c|}
\hline Item & 30 Sept. 1982 & 23 Aug. 1983* & 13 Sept. 1983 & 20 Aug. 1984 \\
\hline $\operatorname{MCV}$ (normal $80-100 \mathrm{fl}$ ) & 105 & 104 & 102 & 94 \\
\hline $\mathrm{Hgb}$ (normal $13.5-16.7 \mathrm{~g} / \mathrm{dl}$ ) & 12.4 & 12.1 & 12.4 & 12.4 \\
\hline Serum Cbl (normal 207-1098 pg/ml) $\ddagger$ & $237,230 \S$ & 47 & & \\
\hline Serum folate (normal $2.4-17.5 \mathrm{ng} / \mathrm{ml}$ ) & $14.0,13.1 \S$ & 10.0 & & \\
\hline Anti-intrinsic factor-blocking antibodies (normal, absent) & present $\S$ & present & & \\
\hline Serum methylmalonic acid (normal $19-76 \mathrm{ng} / \mathrm{ml}$ ) & $269 \S$ & 338 & 32 & \\
\hline $\begin{array}{l}\text { Urine methylmalonic acid (normal } 810-3830 \mathrm{ng} / \mathrm{mg} \\
\text { creatinine) }\end{array}$ & No sample & 11,000 & 1,480 & \\
\hline
\end{tabular}

* The patient started receiving monthly intramuscular injections of $1 \mathrm{mg} \mathrm{CN}$-Cbl on $8 / 23 / 83$ after the serum and urine were collected. $\ddagger$ Radiodilution assay using purified intrinsic factor $(>95 \%)$ as the Cbl-binding protein. $\S$ These values were obtained on the serum sample taken 30 Sept. 1982, tested in early August 1983.

low serum Cbl level. In September 1982 she was asymptomatic but noted to have an MCV of 105 which led to the performance of serum $\mathrm{Cbl}$ and folate assays which gave normal values. This serum was stored for almost 1 yr while the serum methylmalonic acid assay was being developed, and gave an elevated value of $269 \mathrm{ng} / \mathrm{ml}$ when it was finally assayed in August 1983. Repeat assays in August 1983 for serum $\mathrm{Cbl}$ and serum folate on the August 1982 sample were again normal, and anti-intrinsic factorblocking antibodies were assayed and found to be present. In August 1983 the patient was recalled to clinic where her MCV was essentially unchanged. The serum methylmalonic acid level was still elevated at $338 \mathrm{ng} / \mathrm{ml}$ and methylmalonic acid was elevated in the urine, but the serum $\mathrm{Cbl}$ level was now markedly decreased. 3 wk after receiving an injection of $\mathrm{Cbl}$, serum and urine methylmalonic acid levels had fallen to within the normal range and, when rechecked a year later, the MCV was 94 . No neuropsychiatric symptoms were noted at any time. A high unsaturated Cbl-binding capacity (24) is an unlikely explanation for this patient since her white blood cell count has never (September 1982-present) been elevated and her unsaturated Cblbinding capacity was normal $(2.1 \mathrm{ng} / \mathrm{ml})$ just before treatment with Cbl (August 1983). Unfortunately, Cbl-binding capacity was not measured on the September 1982 sera.

\section{Discussion}

Our studies demonstrate that the assay of methylmalonic acid in serum provides useful information in patients with $\mathrm{Cbl}$ deficiency. The fact that the serum methylmalonic acid level was elevated in 69 of 73 patients with clinically confirmed $\mathrm{Cbl} \mathrm{de-}$ ficiency and in 7 of the 15 samples from the Cbl-deficient infrequently treated group who lacked hematologic or neurologic abnormalities, suggests that its sensitivity may be similar to that of the serum $\mathrm{Cbl}$ level, although studies of patients with borderline and low normal values for serum $\mathrm{Cbl}$ must be performed before a complete comparison of the two assays can be made. The fact that we have observed a patient in whom a moderate elevation of serum methylmalonic acid preceded the development of a low serum Cbl level suggests that the serum methylmalonic acid level will correctly detect $\mathrm{Cbl}$ deficiency in at least some patients in whom the serum Cbl level does not. Thus, it is likely that the serum methylmalonic acid assay and the serum $\mathrm{Cbl}$ assay will complement each other, and that using both assays will make it possible to define the true incidence of $\mathrm{Cbl}$ deficiency in various patient populations (20-23) in a more thorough manner than would be possible with either test alone. The specificity of the serum methylmalonic acid assay for $\mathrm{Cbl}$ deficiency may prove to be greater than that of the serum $\mathrm{Cbl}$ level, which is frequently low in patients with no clinical evidence of deficiency or of an underlying condition affecting Cbl balance (16-19). The test may also prove to be useful in the evaluation of patients with megaloblastic anemia in whom serum levels of both $\mathrm{Cbl}$ and folate are subnormal.

The serum methylmalonic acid level has one advantage that is not shared by the serum $\mathrm{Cbl}$ level in that one can treat a patient suspected of being Cbl-deficient with $\mathrm{Cbl}$ and observe the effect on the serum methylmalonic acid level. If such treatment results in a decrease in the serum methylmalonic acid level from the elevated to the normal range, this is strong presumptive evidence that the patient was Cbl-deficient, as was the case with the patient described in detail in this report. This advantage is not shared by the serum Cbl level, since serum levels of $\mathrm{Cbl}$ are essentially always elevated or at least normal after parenteral injections of $\mathrm{Cbl}$, regardless of whether a patient is $\mathrm{Cbl}$-deficient or not.

Mild, but significant, elevations in serum methylmalonic acid were observed in 5 of 16 folate-deficient patients who had normal serum Cbl levels. Two of these five patients had hepatomegaly and/or abnormal liver function tests and three had no evidence of liver disease. Studies involving measurements of urinary methylmalonic acid have also shown mild elevations in a few patients with folate deficiency (3), but it is not known if this is due to mild coincidental $\mathrm{Cbl}$ deficiency or to some other unknown cause. Recent studies have shown that the amount of $\mathrm{Cbl}$ in various tissues is insufficient to saturate both Cbl-dependent enzymes $(27,28)$. It is possible that in folate deficiency an attempt is made to increase levels of methionine synthetase activity by increasing the amount of $\mathrm{Cbl}$ bound to methionine synthetase with the result that the amount of $\mathrm{Cbl}$ bound to L-methylmalonyl-CoA mutase is decreased, and that this in turn results in increased formation of methylmalonic acid (see Fig. 1).

Levels of serum methylmalonic acid were not correlated with levels of serum $\mathrm{Cbl}$ in the Cbl-deficient patient group. A correlation between $\mathrm{Cbl}$ levels and levels of urinary methylmalonic acid was observed previously in some studies $(3,5)$ but not in 
others $(1,8,9)$. The failure to find correlations between serum methylmalonic acid levels and any of the hematologic parameters, except for a weak inverse correlation with platelet count, is in agreement with studies employing levels of urinary methylmalonic acid (1-12).

Previous workers, studying small numbers of patients with neurologic abnormalities, have found no correlation with urine levels of methylmalonic acid $(3,4,8,9)$ or have suggested a possible relationship $(2,10-12)$. The positive correlation between serum methylmalonic acid levels and the presence of neurologic abnormalities in our large series of patients is of interest, since the biochemical mechanisms responsible for the neurologic abnormalities in $\mathrm{Cbl}$ deficiency are still unknown. The positive correlation between serum folate levels and serum methylmalonic acid levels has also not been noted in studies of urinary methylmalonic acid levels (1-9). This correlation could be due to the fact that patients on diets with relatively high folate contents might have fewer hematologic abnormalities, possibly resulting in a delay in the diagnosis of $\mathrm{Cbl}$ deficiency. The fact that values for serum folate were not positively correlated with any hematologic parameter makes this unlikely, however. It is also possible that some unknown metabolic or regulatory relationship exists between L-methylmalonyl-CoA mutase and methionine synthetase in addition to the fact that they both require Cbl for activity.

\section{Acknowledgments}

We thank Dr. David Savage for help in review of patients' records, and Ms. Maria Ignacio for expert assistance in preparing the manuscript.

This work was supported by Department of Health, Education, and Welfare grant AM21365, awarded by the National Institute of Arthritis, Diabetes, and Digestive and Kidney Diseases; and Individual Fellowship Award GM09968, awarded by the National Institute of General Medical Sciences.

\section{References}

1. Cox, E. M., and A. M. White. 1962. Methylmalonic acid excretion: an index of vitamin $B_{12}$ deficiency. Lancet. ii:853-856.

2. Kahn, S. B., W. J. Williams, L. A. Barness, D. Young, B. Shafer, R. J. Vivacqua, and E. M. Beaupre. 1965. Methylmalonic acid excretion, a sensitive indicator of vitamin $B_{12}$ deficiency in man. J. Lab. Clin. Med. 66:75-83.

3. Brozovic, M., A. V. Hoffbrand, A. Dimitriadou, and D. L. Mollin. 1967. The excretion of methylmalonic acid and succinic acid in vitamin $B_{12}$ and folate deficiency. Br. J. Haematol. 13:1021-1032.

4. Contreras, C., and A. J. Giorgio. 1972. Leukocyte methylmalonylCoA mutase. I. Vitamin $B_{12}$ deficiency. Am. J. Clin. Nutr. 25:695-702.

5. Chanarin, I., J. M. England, C. Mollin, and J. Perry. 1973. Methylmalonic acid excretion studies. Br. J. Haematol. 25:45-53.

6. Frenkel, E. P., and R. L. Kitchens. 1975. A simplified and rapid quantitative assay for propionic and methylmalonic acids in urine. $J$. Lab. Clin. Med. 85:487-496.

7. Norman, E. J., O. J. Martelo, and M. D. Denton. 1982. Cobalamin (vitamin $B_{12}$ ) deficiency detection by urinary methylmalonic acid quantitation. Blood. 59:1128-1131.

8. Bashir, H. V., H. Hinterberger, and B. P. Jones. 1966. Methyl- malonic acid excretion in vitamin $\mathrm{B}_{12}$ deficiency. Br. J. Haematol. 12: 704-711.

9. Frenkel, E. P., and R. L. Kitchens. 1977. Applicability of an enzymatic quantitation of methylmalonic, propionic, and acetic acids in normal and megaloblastic states. Blood. 49:125-137.

10. Vivacqua, R. J., R. M. Myerson, D. J. Prescott, and J. L. Rabinowitz. 1966. Abnormal propionic-methylmalonic-succinic acid metabolism in vitamin $B_{12}$ deficiency and its possible relationship to the neurologic syndrome of pernicious anemia. Am. J. Med. Sci. 251:507-515.

11. Gompertz, D., J. Hywel Jones, and J. P. Knowles. 1967. Metabolic precursors of methylmalonic acid in vitamin $\mathrm{B}_{12}$ deficiency. Clin. Chim. Acta. 18:197-204.

12. Green, A. E., and G. D. Pegrum. 1968. Value of estimating methylmalonic acid excretion in anemia. Br. Med. J. 3:591-592.

13. Kovachy, R. J., S. D. Copley, and R. H. Allen. 1983. Recognition, isolation, and characterization of rat liver D-methylmalonyl coenzyme A hydrolase. J. Biol. Chem. 258:11415-11421.

14. Stabler, S. P., P. D. Marcell, and R. H. Allen. 1985. Isolation and characterization of $\mathrm{D}, \mathrm{L}$-methylmalonyl coenzyme A racemase from rat liver. Arch. Biochem. Biophys. 241:252-264.

15. Marcell, P. D., S. P. Stabler, and R. H. Allen. 1985. Quantitation of methylmalonic acid and other dicarboxylic acids in normal serum and urine using capillary gas chromatography-mass spectrometry. Anal. Biochem. 150:58-66.

16. Dawson, D. W. 1984. Diagnosis of vitamin $B_{12}$ deficiency. Br. Med. J. 289:938-939.

17. Lindenbaum, J. 1983. Status of laboratory testing in the diagnosis of megaloblastic anemia. Blood. 61:624-627.

18. Schilling, R. F., V. F. Fairbanks, R. Miller, K. Schmitt, and M. J. Smith. 1983. Improved vitamin $B_{12}$ assays: a report on two commercial kits. Clin. Chem. 29:582-583.

19. Beck, W. S. 1983. The assay of serum cobalamin by Lactobacillus leichmannii and the interpretation of serum cobalamin levels. Methods Hematol. 10:31-50.

20. Magnus, E. M., J. E. Bache-Wiig, T. R. Anderson, and E. Melbostad. 1982. Folate and vitamin $B_{12}$ (cobalamin) blood levels in elderly persons in geriatric homes. Scand. J. Haematol. 28:360-366.

21. Nexo, E. 1983. Variation with age of reference values for $\mathbf{P}$ cobalamins. Scand. J. Haematol. 30:430-432.

22. Evans, D. L., G. A. Edelsohn, and R. N. Golden. 1983. Organic psychosis without anemia or spinal cord symptoms in patients with vitamin $B_{12}$ deficiency. Am. J. Psychol. 140:218-221.

23. Cole, M. G., and J. F. Prchal. 1984. Low serum vitamin $B_{12}$ in Alzheimer-type dementia. Age Ageing. 13:101-105.

24. Corcino, J. J., R. Zalusky, M. Greenberg, and V. Herbert. 1971. Coexistence of pernicious anaemia and chronic myeloid leukemia: an experiment of nature involving vitamin $\mathrm{B}_{12}$ metabolism. Br. J. Haematol. 20:511-520.

25. Metz, J., A. Kelly, V. C. Swett, S. Waxman, and V. Herbert. 1968. Deranged DNA synthesis by bone marrow from vitamin $B_{12}$-deficient humans. Br. J. Haematol. 14:575-592.

26. Wickramasinghe, S. N. The deoxyuridine suppression test. In The Cobalamins. C. A. Hall, editor. Churchill Livingstone Inc., New York. 196-208.

27. Kolhouse, J. F., and R. H. Allen. 1977. Recognition of two intracellular cobalamin-binding proteins and their identification as methylmalonyl-CoA mutase and methionine synthetase. Proc. Natl. Acad. Sci. USA. 74:921-925.

28. Kondo, H., M. Osborne, J. F. Kolhouse, M. J. Binder, E. R. Podell, and R. H. Allen. 1981. Nitrous oxide has multiple deleterious effects on cobalamin metabolism and causes decreases in the activities of both mammalian cobalamin-dependent enzymes in rats. J. Clin. Invest. 67:1270-1283. 